\title{
In memoriam Beat Richner (1947-2018)
}

Ein tanzender Clown. Ein Clown, der von jeder unangenehmen Untersuchung, ja sogar von Nadelstichen bei Impfungen, ablenkte - daran erinnert sich wohl jedes Kind, das bei Beat Richner in dessen Zürcher Praxis, seinem «Lädeli», behandelt wurde. Die Ablenkung wirkte: Mein Bruder und ich gingen vor rund vierzig Jahren stets gerne zu Beatocello, der auf seinem Instrument mitunter traurig klingende Lieder spielte und sang, die wir nicht immer ganz verstanden. Wir gingen, bis Beat 1992 seine Koffer packte und nach Kambodscha aufbrach, dem Ruf des damaligen Königs Sihanouk folgend.

Es war nicht sein erster Besuch dort: Bereits als junger Assistenzarzt absolvierte Beat Richner für das Rote Kreuz einen Hilfseinsatz in dem vom Vietnamkrieg mitgenommenen Land. Doch als die Roten Khmer unter Pol Pot die Macht übernahmen und einen menschenverachtenden Bürgerkrieg anzettelten, musste er das Land Hals über Kopf auch wieder verlassen. Die intellektuelle Elite Kambodschas wurde in den Killing
Fields ausgelöscht, und das Land wie seine Bevölkerung versanken in tiefe Armut. Die desaströsen Konsequenzen trugen wie so oft die Schwächsten: die Kinder.

Ihnen widmete Beat Richner sein Lebenswerk. «Es liegt in der Verantwortung des Westens, für die Ärmsten der Armen einzustehen" - so sein Credo, an das er seine unzähligen Schweizer Spenderinnen und Spender immer wieder erinnerte. Denn «nicht die Armut an sich, sondern die Diskriminierung der Armen ist der Grund hoher Sterblichkeit der Kinder der armen Welt».

«Seine» Kinder in Kambodscha sollten deshalb die gleiche Medizin erhalten wie jedes Kind in der Schweiz und zwar gratis. Diese Einstellung war und ist bis heute einzigartig in der Entwicklungshilfe. Und sie trug Früchte: Fünf Jahre Kambodscha waren geplant, aus ihnen wurden fast 25. Es waren Jahre harter Arbeit, deren Ergebnisse jedermann bestaunen kann. Nicht weniger als fünf Spitäler in Phnom Penh und Siem Reap

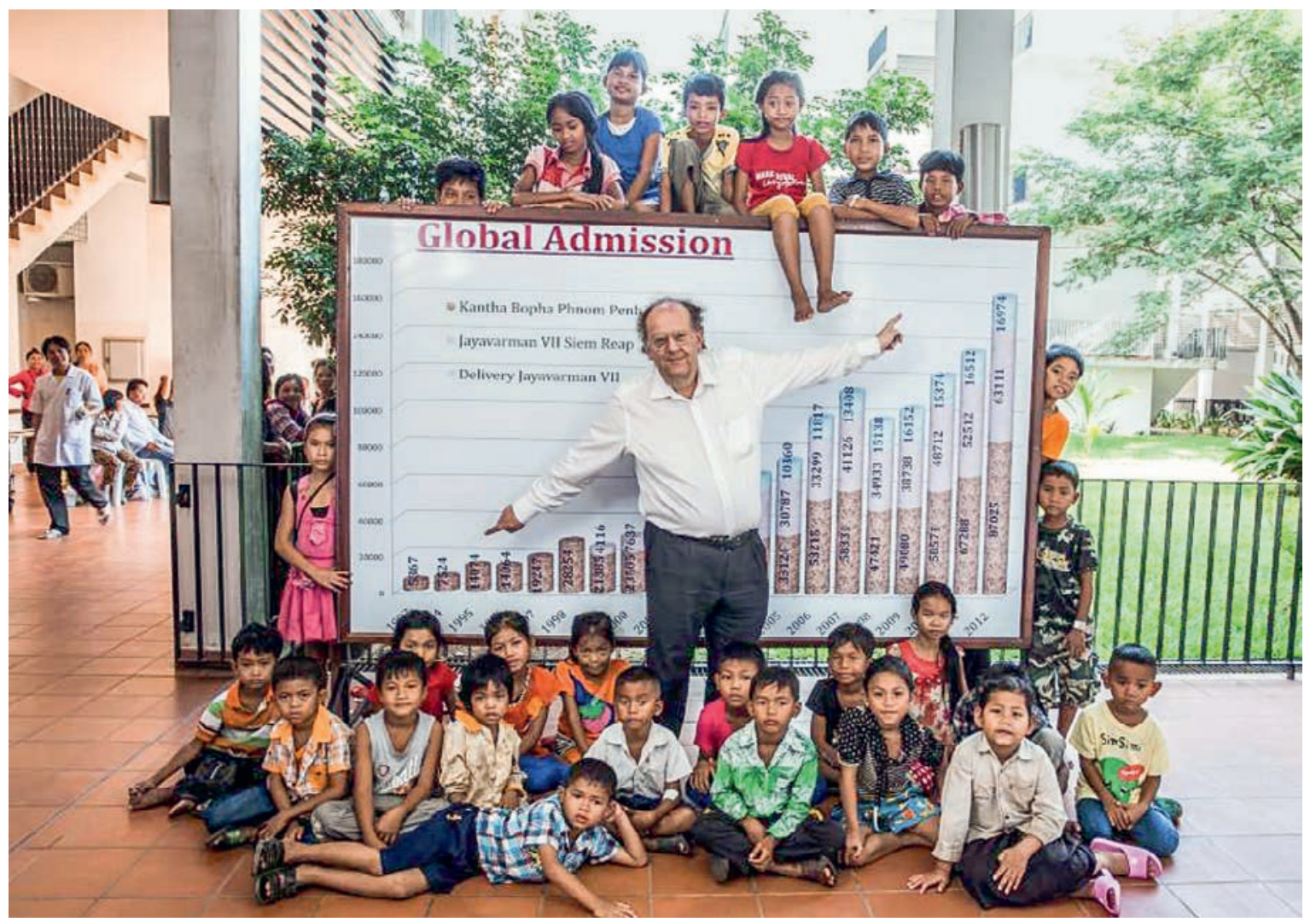




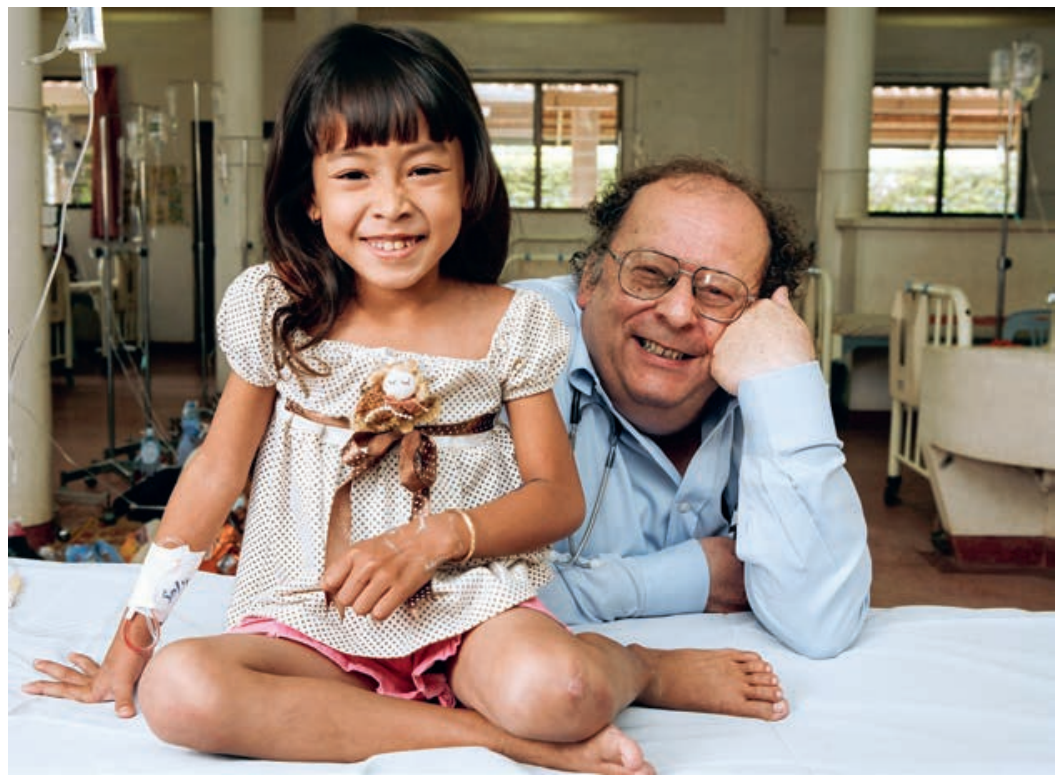

wurden dank seiner Hilfe errichtet. 1992 eröffnete sein erstes Kinderspital: Kantha Bopha I. Mit jedem Tag, den die Spitäler existierten, wurden die Warteschlangen geduldig wartender kambodschanischer Familien vor den Toren länger. Aus- und Neubauten kündigten sich damit früh an: 1996 wurde Kantha Bopha II in Phnom Penh errichtet, 1999 das Jayavarman VII in Siem Reap eingeweiht. Richner gründete hier eine Maternité, in der allein im Jahr 201725357 Geburten verzeichnet wurden. Durch eine gute und korrekte Schwangerschaftsvorsorge und die Identifizierung von HIV-positiven Müttern können heute Virusübertragungen auf Neugeborene vermieden werden.

2005 und 2007 kamen schliesslich Kantha Bopha IV und V hinzu. Des Weiteren wurde ein Herzzentrum mit interventionellem Herzkatheter 2011 eröffnet, um Kinder mit angeborenen Herzmissbildungen zu helfen. All das war nur möglich, da die gesamte Infrastruktur der Spitäler auf hohem Niveau funktionierte: Die Labors, die Intensivstationen, die Blutbanken und die diagnostischen Mittel - sie alle sind vergleichbar mit denen in der Schweiz.

Aber das hohe Niveau hatte seinen Preis: Beat Richners Alltag war hart und mühsam. Als ich 2004 die Möglichkeit hatte, als Praktikantin einige Wochen in Siem Reap zu arbeiten, war das in jeder Sekunde spürbar: Beat war von früh bis spät auf Trab, er hatte kaum soziale Kontakte darüber hinaus. Die Sorge um die Kinder und das Elend waren allgegenwärtig, die Kritiken von daheim, er betreibe «Rolls-Royce»-Medizin, oft zermürbend. Tat- sächlich kämpfte er ums Geld, um jeden Rappen: Auf seinen "Betteltouren», wie er das Spendensammeln zwischen dem Zürcher Bellevue und Einsiedeln manchmal etwas bitter nannte, gelang es ihm Jahr für Jahr, mehrere Millionen für seine Spitäler zu sammeln.

Sein Einsatz lohnte sich: Seit nunmehr 26 Jahren werden in Kambodscha tagtäglich Kinder (mittlerweile bereits die dritte Generation) behandelt, geimpft und gerettet. Sie erfahren in Kantha Bopha und Jayavarman VII häufig erstmals so etwas wie Gerechtigkeit, denn hier hat die sonst allgegenwärtige Korruption keinen Platz. Unter den mittlerweile 2500 Mitarbeitenden (vom Chefarzt bis zum Reinigungsfachangestellten) wächst eine neue Generation von Medizinern in Kambodscha heran, die für die Zeit nach Beats Engagement ausgebildet ist. Die jungen Ärzte erhalten eine Ausbildung, die mit jener in der Schweiz vergleichbar ist. Professoren des Universitäts-Kinderspitals Zürich reisen seit Jahrzehnten regelmässig nach Kambodscha und unterrichten dort in ihren jeweiligen Spezialgebieten.

Im Frühling 2017 musste Beat Richner wegen einer neurodegenerativen Erkrankung die Leitung der Spitäler abgeben und sich in Behandlung in die Schweiz begeben. Der Spitalbetrieb läuft seither ohne Probleme weiter - die neuen kambodschanischen Ärzte und auch Richners langjährige Wegbegleiter Denis Laurent und Peter Studer sorgen dafür. Auch die Spenderinnen und Spender in der Schweiz bleiben den Projekten treu, ausserdem unterstützt das DEZA - und nicht zuletzt übernimmt auch die kambodschanische Regierung nach und nach mehr finanzielle Verantwortung.

Eine Reise im Auto ums Mittelmeer wolle er noch machen, diesen Wunsch äusserte Beat mir gegenüber einmal. Das Schicksal hatte einen anderen Plan: Statt den wohlverdienten Lebensabend geniessen zu dürfen, löschte sich sein Erinnerungsvermögen langsam aus, es ging ohne Leiden. Unbewusst hat er die Zügel seiner Spitäler losgelassen, an eine kompetente kambodschanische Crew abgegeben, genau so, wie er es immer gewollt hatte.

Am 9. September dieses Jahres ist Beat Richner im Alter von 71 Jahren gestorben. Die Anteilnahme in Kambodscha und der Schweiz ist überwältigend.

Dr. med. Seraina Prader, Oberärztin Immunologie, Universitäts-Kinderspital Zürich; Stiftungsrätin Stiftung Kinderspital Kantha Bopha, Dr. med. Beat Richner

Bildnachweis

() Fotos: Monika Flückiger 